\title{
Free Recall Trial 5
}

National Cancer Institute

\section{Source}

National Cancer Institute. Free Recall Trial 5. NCI Thesaurus. Code C120403.

The final free recall task from the California Verbal Learning Test, second edition. 